\title{
Editorial Introduction \\ The Inaugural Special Topics Issue \\ On Resurfacing Tragedy
}

\author{
JOHN DUNCAN
}

Welcome to the inaugural special topics issue of PhaenEx, the electronic journal of the Canadian-based, international and interdisciplinary society for the study of existential and phenomenological theory and culture / la société pour l'étude de la théorie et la culture existentialiste et phénoménologique (EPTC/TCEP). PhaenEx will publish two issues each year, an annual Spring/Summer open issue, and an annual Fall/Winter special topics issue. Although this issue (the second number of two in the first volume of the journal) has come out about six months late, and although the next issue (the first number of the second volume) will come out about one month late, subsequent issues are now well underway in order to meet the twice yearly seasonal deadlines. Authors both inside and outside of EPTC/TCEP are warmly invited to make submissions to the journal. Submissions are to be made using the Online Journal Software on the PhaenEx website, and are subject to peer review. For more information contact the current Chair of the PhaenEx Editorial Collective, whose contact information is available on the website.

\section{On Resurfacing Tragedy}

On Resurfacing Tragedy had its beginnings in a search for papers for an extended panel session dealing with tragedy, to be included in the EPTC/TCEP annual conference at York University in Toronto in late May 2006. The initial search turned up excellent prospects. The panel 
consisted of the presentation of eight papers, each with a formal respondent and lively discussion, conducted over the course of two long afternoons. After the conference, submissions were invited for publication review from delegates and others who had indicated interests in the topic. Except for the two invited introductory articles, all the articles in On Resurfacing Tragedy are reworked papers from the panel. I am very pleased with the result.

\section{The Two Invited Introductory Articles, on Aristotle and on Hegel}

The two invited articles are basic introductions to tragedy—one to tragedy in Aristotle, the other to tragedy in Hegel—arguably the two most important theorists of tragedy before the principal authors discussed in the other four papers in the issue. Each of the two introductory articles provides much more than a typical editorial introduction might provide with respect to the discussion of an important precursor, but remains introductory and relatively brief in order to maintain the existential and phenomenological focus overall.

Not too long ago, John Baxter, who was invited to write the introductory article on Aristotle, co-edited an edition of Aristotle's Poetics. In his article published here, he not only introduces us to the main concepts in Aristotle's main work on tragedy, but in the all too brief ten pages at his disposal he also does an excellent job of suggesting that we keep important questions open in this field, a field over which scholarship has trudged back and forth for over two thousand years. "Aristotle's principles may appear sharp and well-defined, even schematic, but that impression would hide something of their profoundly exploratory quality, covering a wide range of disparate evidence," argues Baxter. Although the article is introductory, even those who have studied Aristotle's Poetics in the past are likely to find something to think about in "The Soul of 
Tragedy: Some Basic Principles in Aristotle's Poetics," which is framed by the centrality of plot (in tragedy) as the animus of a complicated and moving but single action rendered dramatically and in a way that reveals something serious about human experience.

Even where he does not make an explicit appearance, Aristotle is almost always in the background of discussions about tragedy, and he had an immense influence on Hegel. If we can say that the influence of Aristotle is ubiquitous with respect to discussions of tragedy generally, the same can be said about the influence of Hegel if we narrow the field to the late modern continental tradition. Mark W. Roche, who was invited to write the introductory article on Hegel, recently contributed an excellent article on Hegel and tragedy to the very useful 2005 Companion to Tragedy, edited by Rebecca Bushnell. His article for On Resurfacing Tragedy, "Introduction to Hegel's Theory of Tragedy," very clearly and succinctly introduces Hegel's texts and ideas on tragedy. "For Hegel tragedy is the conflict of two substantive positions, each of which is justified, yet each of which is wrong to the extent that it fails either to recognize the validity of the other position or to grant it its moment of truth; the conflict can be resolved only with the fall of the hero," Roche argues. Readers would do well to think through the concepts Roche introduces before reading the extended articles that follow, for there are many links-some comparative, others contrastive - that could be traced between Hegel on the one hand and Kierkegaard, Nietzsche and Heidegger on the other hand.

\section{Kierkegaard, Nietzsche, Heidegger}

Following the two invited introductory articles, there are four extended discussions of tragedy, in Kierkegaard, in Nietzsche's Birth of Tragedy, in Nietzsche's Daybreak, and in 
Heidegger. In the first, "Kierkegaard on Abraham's Tragedy: the Loss of Community," Elsebet Jegstrup provides a provocative analysis of Kierkegaard's Abraham as a uniquely chosen founder who is tragically differentiated from his followers. Abraham's role is tragic because he has been called to what we cannot comprehend, which requires that he suffer the loss of community. But community and its ethos is the ground of concrete life, something to which the chorus in Greek tragedy gave a voice. Those who stray from it, do so at their peril. Abraham stands outside its range, analogous in interesting ways to the atomized individual of modern commercial society who has also been severed from any substantive ethical background, and so also suffers a tragic loss. According to Jegstrup, Kierkegaard provides analyses that suggest that Abraham is something of a reckless abstraction, whereas each of us ought to respond concretely to the call of love of the other, and in so doing overcome both Abraham's loss, and the analogous degeneration of modern society. For Kierkegaard, the ethical community is the ground of human flourishing; outside of its range we are a non-community based on self-motivated contractual interactions, in which each self is an atomized abstraction or caricature of what it ought to be, suffering a loss virtually as great as Abraham's. Just as for Hegel, for Kierkegaard the ethical substance of the community is necessary for the concrete flourishing of each individual, but Hegel's long history of contestations of particular stages of community as the way to the community that recognizes its truth in freedom is rejected. Rather love alone, something of which each of us is immediately capable, must rebuild the post-contractual community and reintegrate the individual in its ground.

In the second extended discussion, "Culture, Tragedy and Pessimism in Nietzsche's Birth of Tragedy," my own contribution to the issue, I look at The Birth of Tragedy, Nietzsche's first published book. Beginning from Nietzsche's own later critical look back at the book, I argue that 
in lamenting both the influence of Schopenhauer, and the inclusion of extended criticism of contemporary German culture, Nietzsche does not do justice to the interdependence of these elements and his analysis of tragedy and its significance in the book. In The Birth of Tragedy's very Schopenhauerian, godless cosmos, all encounterable things, though apparently determinate, ultimately exist without ground. Humans intersect the underlying noumenal abyss and the evanescent determinations of quotidian life, but modern "theoretical" humanity has come to believe that all things can be fully fathomed, understood and reformed, especially by using the concept of causality. Kant and Schopenhauer have returned us to the perspective of the abyss (which was first encountered in Anaximander and in Aeschylean tragedy), perhaps inaugurating a healthy pessimism that might delimit theoretical humanity's delusional optimism. A new tragic culture seemed to be possible. For Nietzsche, the meaning of tragedy is rooted in what we find him taking from Schopenhauer's pessimism, but in the end, although Nietzsche's expressed understanding of tragedy in these early years draws heavily on Schopenhauerian pessimism, it nevertheless exceeds that influence. We need to be attentive to the various phenomena we label tragic, and glimpse what holds sway just beneath their surfaces to understand the individual's selfsurrender to the ineffable power of the abyss in tragic drama, a groundless grounding that belies the incredible strength of early ancient Greek culture in contrast to the unfounded and disastrous optimism that followed it.

In "The Spectacle of Suffering: On Tragedy in Nietzsche's Daybreak," the third extended article below, Thomas Bartscherer leads us through a wonderful analysis of tragedy in Nietzsche's Daybreak, a text Nietzsche later claimed was the beginning of his assault on morality. Because the spell of morality's seduction is rooted in charms that lie deep below mere argumentation, tragedy, 
with its equally deep roots, might be useful in breaking the spell, reinvigorating perhaps a healthy philanthropy that would echo early ancient Greek culture. The pleasure to be had in the tragedy of The Birth of Tragedy was, a decade later in Daybreak, reexamined and traced back to the enjoyment of the spectacle of cruelty, which Nietzsche would find at the root of both moral psychology and tragic pleasure. He mobilized the pleasures of tragedy against the seductions of morality, as he probed the very nature of desire and suffering. In the end, Bartscherer argues, Nietzsche invoked a passion for honesty, for knowing-i.e., a self-sacrificing suffering in the service of knowledge — as the most uplifting goal for humanity, an alternative to the pitiful and guilt-ridden Christian and Kantian cultural-historical tradition of moralism.

The fourth and final article, "The Tragic Double Bind of Heidegger's Techne," by David Edward Tabachnick, nicely reveals the tragic fatalism at the heart of Heidegger's musings on technology. Although original techne worked nature over, it did so without any illusion of altering nature permanently. However, the Platonic projection of the universal and eternal idea of each thing became the animus of a cultural-historical process that led to the technological reduction of nature to our scientific and theoretical ideas of it. Of course, technology frees us from many of the burdens of nature, but its very freedom and its mastery of nature threaten both to forget nature completely, and to eclipse humanity. We are no longer in charge of technology, and its essence now applies itself ever more threateningly to us, remaking us in its own image and failing to heed its own limits. Because the results of original techne were temporary, always being undone by the return of nature, they were sites of the disclosure of overpowering nature, our ground. We no longer experience that disclosure, and so we are threatened with the loss of our relation to our ground. But we may yet be returned to the disclosure, for the destiny of technological culture 
threatens us with catastrophe, which in turn, turns us toward itself as overpowering nature. Tragically, salvation is bound to the danger itself.

If Kierkegaard worried that modern society had the effect of severing each of us from community, our essential and ethical back-ground, we might say that Heidegger worried that technology was severing us from our essential and ontological back-ground. And like the early Nietzsche, who saw in the theoretical work of Kant and Schopenhauer the self-delimitation of theoretical humanity, Heidegger saw heralds of possible salvation in the danger itself.

In each of these articles, ancient Greek tragedy, which received what became its virtually canonical analysis in Aristotle, resurfaces. It is perhaps not insignificant that between the early nineteenth century and the late twentieth century, following the period of the European enlightenment and its historical self-understanding in Hegel and others, Kierkegaard, Nietzsche, and Heidegger returned to ancient Greek tragedy, re-surfacing it, each in his own way, in order to mobilize it in deeply critical assessments of what we have become. Are we atomized, overly contractual in our inter-relations? Could we love the other? Would love check the war and genocide that plague us? Have we been turned away from nature and our finitude in an extended fit of overly optimistic scientism and technological inertia? Could the threats of global climate change, genetically modified humanity, weapons of mass destruction proliferation, and the virtually eternal toxicity of nuclear waste be dangers sufficient to turn us to examine what may be the destiny of an unfolding catastrophe? Can we be turned and respond appropriately? Are we fighting against each other, as so many fundamentalists across the planet, each caught within a moral psychology of weakness, and unable to overcome blind judgement of the other? Could a healthy passion for honesty and knowledge help us trace our grandiose and ideological 
presuppositions - on the basis of which we ignore, silence, judge, murder others-back to their origins in basic desires? Could the abyss draw us back to a healthy acceptance of the finitude of all things, to absorb the fact of pain and suffering, such that we might laugh at the pettiness of our moralizing and overcome it? These questions seem to lie just below the alienated, delusionally optimistic, moralistic, and technologically crazed surface of late modern western social and political reality. Perhaps ancient Greek tragedy is useful in addressing them.

\section{Acknowledgements}

On Resurfacing Tragedy was made possible by many good people. Paul Gyllenhammer handled the publication review of the Lead Editor's submission. Astrida Neimanis, Ian Angus, and Lisa Guenther provided valuable copy-editing advice. EPTC/TCEP and PhaenEx reviewers, who must remain nameless, refereed submissions, both for the original conference panel and for the journal issue. The organizers and delegates at the 2006 conference facilitated and inaugurated the discussion. And the authors have provided us with the feast of discourse we have before us. My thanks go to each of them. 